\title{
TRAJETÓRIAS SOCIOESPACIAIS DE CAMPONESES (E)MIGRANTES E A LUTA PELA TERRA
}

\section{Socio-Spatial Trajectories of Emigrating Peasants and the Struggle For Land}

Prof ${ }^{\mathrm{a}}$. Dr ${ }^{\mathrm{a}}$. Dinalva Donizete Ribeiro

Programa de Pós-graduação em Geografia da Universidade Federal de Goiás/ Campus Jataí Rua Riachuelo, n. ${ }^{\circ} 1530$, CEP: 75.800-000 - Jatai (GO) - Brasil Tel/Fax: (+55 64) 3632-0003/3632-0002 - dinalvadr@gmail.com

Profa. Msc. Juliana Carneiro Guimarães

Universidade Federal de Goiás/Campus Jataí Juguimaraes2004@gmail.com

\section{${ }_{a} a \boldsymbol{a}_{a}$}

\begin{abstract}
Resumo
O artigo apresenta dados, análises e discussões sobre as trajetórias socioespaciais dos camponeses do Projeto de Assentamento Rio Claro (PARC), localizado no município de Jataí, na Microrregião Sudoeste de Goiás. A discussão foi organizada a partir de duas fases da trajetória dos camponeses pesquisados. Na primeira evidencia-se aspectos das suas vidas e da relação com a terra desde a mais tenra idade, bem como os motivos que os levaram a deixar seus núcleos familiares, os caminhos de suas migrações e como chegaram ao município de Jataí. A segunda fase da análise perpassa suas trajetórias ao chegarem a este município sob a condição de sem-terra e, por fim, discute-se como emergiu e transcorreu a luta pela terra da qual os sujeitos pesquisados fizeram parte. Agregam-se a esta análise dados sobre a questão agrária e a luta pela terra na microrregião sudoeste de Goiás.
\end{abstract}

Palavras-chave: Questão agrária, Luta pela terra, Reforma agrária, Campesinato.

\begin{abstract}
The article presents data, analysis and discussions on the socio-spatial trajectories of the peasants of Rio Claro Settlement Project (PARC), in the city of Jataí in Southwestern Goiás Microregion. The discussion was organized from two phases of the trajectory of the surveyed farmers. The first is evident in aspects of their lives and relationship with the land from an early age, and the reasons that led them to leave their households, their migration paths and how they came to the city of Jataí. The second stage of the analysis cuts across their path to reach this city on the condition of the landless and, finally, discusses how the struggle has emerged and went by land from which the subjects surveyed were part of. Add to this data analysis on the agrarian question and the struggle for land in the southwest of Goiás microregion.
\end{abstract}

Key words: Agrarian question, Struggle for land, Agrarian reform, Peasants.

\section{Resumen}

El artículo presenta datos, análisis y discusiones sobre las trayectorias socio-espaciales de los campesinos del Proyecto del Asentamiento Rio Claro (PARC), localizado en el Municipio de Jataí, en la Microregión Sur-oeste de Goiás. La discusión fue organizada a partir de dos fases de la trayectoria de los campesinos investigados. En la primera se evidencia aspectos de sus vidas y de la relación con la tierra desde la más tierna edad, así como los motivos que los llevaron a dejar sus núcleos familiares, los caminos de migración y como llegaron al Municipio de Jataí. La segunda fase de análisis perpassa sus trayectorias al llegar a este municipio sobre la condición de sin-tierra y, por fin, se discute como emergió y transcurrió la lucha por la tierra pen la cual los sujetos investigados hicieron parte. Se agregan a este análisis, datos sobre la cuestión agraria y la lucha por la tierra en la micro-región sur-oeste de Goiás.

Palabras-clave: Cuestión agraria, Lucha por la tierra, Reforma agraria, Campesinato.

\section{aaAa}

Revista da ANPEGE, v. 7, n. 8, p. 53-67, ago./dez. 2011.

ISSN 1679-768 X @ 2003, Associação Nacional de Pesquisa e Pós-Graduação em Geografia. Todos os direitos reservados. 


\section{INTRODUÇÃO}

As reflexões aqui apresentadas são desdobramentos da pesquisa desenvolvida no âmbito do Programa de Pós-Graduação em Geografia da Universidade Federal de Goiás - Campus Jataí, intitulada "As trajetórias socioespaciais dos camponeses do Assentamento Rio Claro". Pretende-se, por meio deste, dar visibilidade à luta pela terra no município de Jataí e na microrregião Sudoeste de Goiás, contribuindo, dessa forma, com as reflexões e o acervo bibliográfico sobre tal temática na região.

A pesquisa considerou as trajetórias socioespaciais dos camponeses do Projeto de Assentamento Rio Claro (PARC) em três fases: a primeira, sendo o período compreendido desde o nascimento dos depoentes, até o momento em que saíram de seus lares paternos; a segunda, que retrata o período em que ingressaram na luta pela terra até serem assentados; a terceira evidencia a fase atual de suas vidas, enquanto assentados do programa de reforma agrária.

No entanto, neste texto se pretende discutir as duas primeiras fases supracitadas, com o objetivo de abordar questões inerentes à questão agrária, à estrutura fundiária do município de Jataí e a luta pela terra na microrregião Sudoeste de Goiás. Os aspectos identificados na pesquisa que não estão aqui abordados podem ser verificados na dissertação da segunda autora, sob orientação da primeira (GUIMARÃES, 2011).

Os dados foram coletados por meio de pesquisa bibliográfica e de campo. Esta se subdividiu em duas etapas: a primeira buscou dados secundários por meio de pesquisa documental, acessando informações disponibilizadas pelo DATALUTA (2008), pelo STR-J e pela Associação representante das famílias do assentamento; a segunda etapa originou dados primários, coletados por meio de questionário semi-aberto, entrevista semi-estruturada e observação participante.

O questionário foi respondido pelas dezessete famílias que residem no assentamento, obtendo a participação de dezenove pessoas, entre homens e mulheres. A partir do questionário e de acordo com o perfil dos camponeses, treze foram selecionados para fazerem o relato de suas trajetórias socioespaciais, que foi conduzido por meio de entrevista semi-estruturada.

Os treze depoentes que narraram suas trajetórias e histórias de vida são citados no decorrer do trabalho como Entrevistado 1, 2 e, assim, sucessivamente, até o número treze, de modo a preservar suas identidades.

Durante a realização das entrevistas tivemos a oportunidade de nos manter no assentamento, com hospedagem no sítio de uma das famílias. Esta situação foi significativa para apreensão de aspectos do cotidiano do assentamento, das famílias e para o nosso crescimento em aspectos pessoais e profissionais. Este processo foi guiado pela observação participante.

O conceito "trajetória" é utilizado com a finalidade de expressar um percurso que os camponeses fazem durante suas vidas, de forma dinâmica e dialética e na sua relação com a macroestrutura social na qual estão inseridos.

Considera-se que as trajetórias representam variadas posições ocupadas sucessivamente por uma mesma pessoa ou grupo, sendo passíveis de transformações incessantes. Evidenciam o caminho percorrido e as opções realizadas, sempre dotadas "[...] de sentido que comporta etapas tendo um começo, um meio e um fim numa sucessão de acontecimentos que não possuem significados unilineares ou unidirecionais" (CIRQUEIRA, 2010, p. 42).

O conceito de socioespacialidade representa a dimensão do espaço como a forma materializada, concreta da realidade onde ocorre a interação constante entre indivíduo/sociedade e suas forças constituintes.

\section{A VIDA NA TERRA SEGUIDA DA TRAJETÓRIA DE MIGRAÇÕES}

A primeira fase das trajetórias socioespaciais dos camponeses pesquisados é tratada a fim de situar o contexto social e histórico dos mesmos quando ainda moravam e trabalhavam com/nos seus 
núcleos familiares originais (com pais, irmãos e, eventualmente, outros parentes próximos), buscando estabelecer relação entre os motivos das suas migrações e trajetórias com a dinâmica mais ampla pela qual o Brasil passava no período de 1940 a 1980, sendo este o momento no qual os sujeitos pesquisados estiveram transitando pelo território brasileiro em busca de terra para trabalhar e viver.

Dentre os dezenove pesquisados, todos viveram no campo, no núcleo familiar, até a adolescência ou a juventude e saíram quando não mais foi possível permanecer com a família, em função, principalmente, do desequilíbrio na relação trabalho-consumo, derivado da desproporção existente entre a terra pequena e a família grande. Quinze deles nasceram no campo e quatro na cidade. Porém, destes somente um não passou o início de sua vida na "roça", os demais, mesmo tendo nascido na cidade, foram para o campo ainda criança.

De acordo com os depoimentos, o núcleo familiar de todos os pesquisados era numeroso e composto por, no mínimo, seis pessoas, entre pai, mãe, irmãos e outros entes da família, como pode ser percebido na fala do Entrevistado 7: "[morava] com o pai, a mãe e os irmãos, nós éramos nove. Nove só os filhos dos velhos".

No local de moradia todos os depoentes tinham contato direto com a terra, sendo "donos", posseiros ou agregados.

Cabe uma ressalva em relação à expressão "dono" da terra, utilizada de forma recorrente pelos camponeses. Aqui utilizamos esta expressão (e outras, como "roça") para ser mais fiel ao vocabulário empregado por eles em relação à posse da terra, pois é sabido que a terra para os camponeses é mais que a propriedade privada, não sendo uma mercadoria passível de especulação, é tida como terra de trabalho e de vida.

Um exemplo que reafirma isto é relatado por Woortmann:

Perguntei a um sitiante se seu pai era proprietário da terra de seu sítio. A resposta foi não, o que me deixou um tanto confusa, pois eu sabia que existiam documentos que atestavam a propriedade. E o sitiante me disse: 'a senhora quer saber se ele era dono, não é?' Proprietário é uma categoria aplicada aos grandes fazendeiros que auferem lucros com o trabalho dos outros. Seu pai era dono 'porque trabalhou a terra e deixou para seus filhos'. Há vários significados envolvidos nessa afirmação. Nos termos dos valores camponeses se é dono por efeito do trabalho (WOORTMANN, 2004, p. 136-137, grifos nossos).

Ao narrarem suas trajetórias socioespaciais e rememorar suas histórias de vida, dez depoentes destacaram que suas famílias eram donas das terras nas quais moravam e, dos nove demais, seis relataram que viviam em terras alheias, sob a condição de agregados e meeiros; dois relataram que eram arrendatários; e um afirmou que sua família vivia sob a condição de posseira, conforme pode ser visualizado no gráfico abaixo.

\section{口PROPRIETÁRIO $\square$ AGREGADO $\square$ ARRENDATÁRIO $\square$ POSSEIRO}

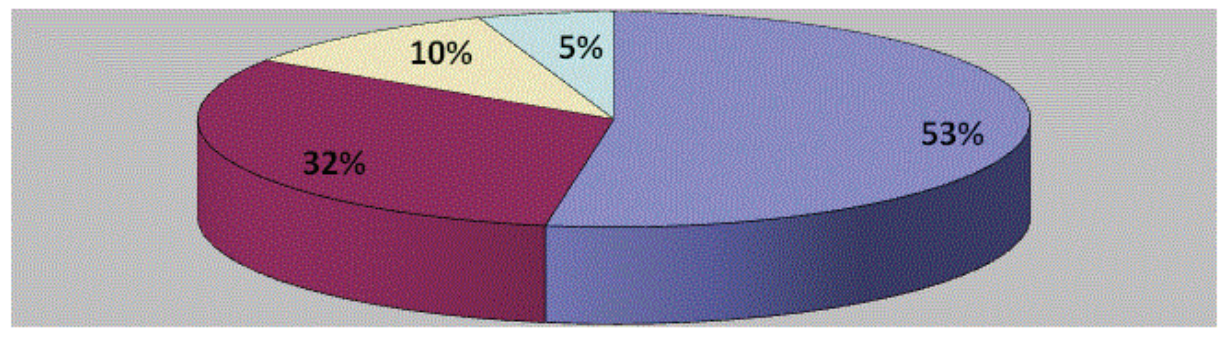

Figura 1 - Gráfico representativo da situação de moradia e de trabalho do núcleo familiar dos depoentes na fase inicial de suas trajetórias

Fonte: dados organizados pelas autoras, pesquisa de campo, 2010. 
Para além da situação em relação à posse da terra, o gráfico 1 dá a dimensão da relação entre terra, trabalho e família, tendo o local de moradia como o lócus de trabalho que envolvia todos os membros da família, num modelo de organização e relação de trabalho próprio do modo de vida camponês. Esta característica marca todas as trajetórias socioespaciais narradas, principalmente no período que remete às décadas de 1940 e 1950.

Sabe-se que o acesso a terra, para moradia e trabalho, é fator fundamental a determinar a permanência ou não das famílias no campo. No caso dos camponeses pesquisados, a dificuldade em permanecer ou em acessar a terra na medida em que foram entrando na idade adulta foi decisiva para que deixassem seus núcleos familiares e migrassem em busca de terras para que, assim, pudessem constituir suas próprias famílias, uma vez que as terras usadas em conjunto por pais e irmãos não eram suficientes para abrigar novos indivíduos, no caso de matrimônios.

Isto se configura no desequilíbrio entre trabalho e consumo, caracterizado pela existência de uma família numerosa, maior do que a terra suporta em termos de trabalho, produção e produtividade. Tal questão está tratada nas análises elaboradas por Paulino e Almeida (2010) e Moura (1988), baseadas na obra de Chayanov (1974), que denominam esta relação entre terra/trabalho/família como balanço trabalho-consumo, onde há uma família numerosa vivendo e trabalhando numa terra pequena, não propiciando condições de trabalho e de vida a todos os seus membros. Dados da pesquisa apontam que este foi o principal motivador da migração dos camponeses investigados.

O depoimento de um dos interlocutores evidencia esta situação e demonstra que há entendimento e consciência de tal circunstância por parte dos camponeses, o que nos leva a observar aspectos emocionais decorrentes, uma vez que ainda jovens, em tenra idade, se viram obrigados a deixar seus lares, terras e famílias e se lançar no caminho errante da migração de forma a buscar terra de trabalho e de vida:

[a terra] era do meu pai e da minha mãe. Um pedacinho pequenininho. Na verdade mesmo, não dava! A família era grande, mas [a terra] era desse tamanhozinho! Mas, aí como o 'trem' não ia dando, na época foi esperneando para poder viver. Eu mesmo vim para cá [Jataí] a primeira vez eu tinha 18 anos (ENTREVISTADO 8).

Nota-se que houve esforço para permanecer na terra e com a família, tendo o jovem, naquela ocasião com 18 anos, deixado sua família e sua região com destino a Goiás somente após ter se constatado que não seria possível manter toda a família (grande) na terra ("pequenininha").

Neste caso, a relação entre a terra com área pequena e a família numerosa evidencia a dificuldade enfrentada para a reprodução social desta, se tornando fator decisivo para que o interlocutor saísse da cidade de São Desidério, no Estado da Bahia, deixasse sua família e sua terra, migrasse para o Estado de Goiás e, posteriormente, entrasse na luta pela terra.

Já no caso em que os núcleos familiares dos depoentes viviam enquanto agregados, meeiros e arrendatários a relação com a terra se dava de forma diferente, pois viviam em terras alheias, fato corriqueiro nas relações de trabalho no campo brasileiro até meados do século passado.

No que tange a estas relações, Marques (2000, p. 44) aponta que "a fazenda era um território de reciprocidade, um território dominado por relações pessoais como o compadrio, sistema de trocas, dependência, que incluía o espaço de vida camponês" e menciona que "a formação do campesinato brasileiro está relacionada com uma existência dependente como agregado no interior das grandes fazendas e como posseiro ou sitiante, ocupando pequenas áreas em terras marginais, tanto do ponto de vista econômico como espacial" (p.12).

Esta situação foi comum a oito camponeses pesquisados, cujos núcleos familiares viviam e eram regidos por relações de trabalho como as tratadas por Marques (2000), sendo seis agregados e dois cujas famílias arrendavam terras de fazendeiros que as possuíam em grande quantidade.

O depoimento de uma das camponesas é elucidativo desta realidade. Ao indagar sobre a sua infância e como morava, ela responde que até ter a idade aproximada de 25 anos sua família vivia 
em uma fazenda no município de Itarumã, "perto do Rio Verdinho" (Estado de Goiás) e diante da pergunta se a terra era deles, responde: "não, fazenda dos outros. Meu pai trabalhava de 'a meio', essas coisas assim, era agregado. [...] só morava lá, a casa era do patrão, meu pai construiu, de pau a pique" (ENTREVISTADA 13).

Ela continua seu depoimento dizendo:

Meu pai trabalhava mais com roça. Era assim, tudo que ele fazia era a meia com o dono da fazenda. E minha mãe trabalhava, trabalhava, mas não ganhava. Às vezes o povo dava, às vezes tava ajudando a fazer um requeijão e dava um, um queijo, o pessoal dava uma ajuda, não só o pessoal da fazenda onde a gente morava, mas os vizinhos de lá (ENTREVISTADA 13).

Nota-se no relato que a família trabalhava muito, incluindo a mulher que "trabalhava, trabalhava", mas não recebia pelo seu labor. Esta situação é recorrente neste tipo de relações de trabalho, no entanto havia outras relações de vizinhança, parentesco, compadrio, conforme tratado por Marques (2000), que colaborava com o sustento das famílias, como as ajudas mencionadas pela interlocutora.

Era comum que a família agregada, rendeira, meeira, residisse por muito tempo numa única fazenda. Este era um rito típico que prevaleceu no meio rural brasileiro até a década de 1960 (período em que a maioria dos camponeses pesquisados era adolescente e jovem).

No entanto, esta prática foi se desfigurando na medida em que a agricultura capitalista avançou no campo brasileiro e acabou por afetar a permanência e a reprodução campesina, comprometendo a geração dos sujeitos pesquisados. Estes, na medida em que cresciam, já não podiam seguir vivendo nas terras junto aos seus núcleos familiares, nas parcelas de terra que outrora foram cedidas aos seus pais para moradia e trabalho.

Isso se deu por um conjunto de elementos, com destaque para o interesse dos proprietários em requerer as terras para colocá-las à exploração capitalista impulsionada pela modernização agrícola e, também, como resultado do receio, por parte dos proprietários, das leis trabalhistas estendidas aos trabalhadores do campo em vigor desde a aprovação do estatuto da terra, no ano de 1964 .

Marques (2000) menciona que o avanço das políticas agrícolas capitalistas ameaçou a reprodução camponesa e, como reação, uma das principais estratégias adotadas pelos camponeses foi migrar para outras regiões em busca de terra para o trabalho. No entender desta autora, o avanço destas políticas também fez com que os pecuaristas ampliassem suas áreas de pastagens e reduzissem "[...] suas lavouras e roças cedidas à meia. O conjunto destes elementos ocasionou a diminuição de moradores agregados nas fazendas e de lavradores sem terra trabalhando em terras alheias, além de conflitos com antigos posseiros" (MARQUES, 2000, p. 43).

Moura (1988, p. 29-30) retrata que camponeses agregados na maioria das vezes foram

[...] despejados pelo fazendeiro, em função do número já excessivo de lavradores ou da supressão das relações de produção calcadas no colonato ou na agregação ou, ainda, em função das pressões de uma legislação trabalhista que criava ou aumentava o ônus financeiro do proprietário para com seus subordinados.

O depoimento dos Entrevistados 5 e 6 expressam esta situação ao mencionar que ao se casarem tiveram que se que mudar das terras onde viviam com seus pais. Quando da realização do matrimônio o Entrevistado 5 tinha 21 anos e morava com os pais e irmãos na condição de agregados; já sua esposa, Entrevistada 6, tinha 16 anos e morava com os pais e irmãos em terras próprias, porém insuficientes para comportar uma nova familia: “[...] Quando nós casamos aí eu mudei para outra fazenda, de um tio dela [da esposa]. Já tinha mulher para zelar, né? Aí tinha que separar barraco".

Tal situação demonstra como ocorria a saída de casa e das terras onde viviam. No conjunto dos depooimentos, verifica-se que os dezenove interlocutores saíram de casa em idades diferentes e de lugares diversos do país, mas sempre guiados por motivos semelhantes. 
Dentre os dezenove, cinco nasceram na Bahia, dois no Rio Grande do Sul, um no Rio Grande do Norte, um em São Paulo e um no Mato Grosso do Sul, num total de dez pessoas que iniciaram suas trajetórias socioespaciais em outros Estados que não Goiás (onde atualmente estão assentados).

Os demais são do Estado de Goiás, sendo cinco do município de Jataí, um de Caiapônia, um de Serranópolis, um de Cassilândia e um de Anicuns. Se considerada as diversas origens geográficas dos pesquisados (dezenove pessoas, de seis estados e quatro regiões diferentes), suas trajetórias socioespaciais elucidam que os problemas resultantes da concentração de terras e da exclusão e expropriação derivadas da modernização agrícola não é um fenômeno isolado, mas presente em todo país, penalizando e sufocando camponeses de diversas regiões.

Esta realidade social, política e econômica fez com que a migração se tornasse um imperativo na vida dos camponeses pesquisados. O Entrevistado 5 nasceu em Macaus, no Rio Grande do Norte e conta que se mudou para o estado de Goiás ainda criança, junto com sua família para morar em uma fazenda no município de Quirinópolis:

A primeira vez que nós viemos, ficamos ali na fazenda do doutor... [inaudível], viemos direto para esta fazenda. Veio de pau de arara, naquela época era pau de arara, nem ônibus tinha, era só estrada de chão nesse mundão aí. E gastou foi seis dias de pau de arara. E foi para essa fazenda lá, aí meu pai foi plantar roça, bater invernada, fazer de tudo lá nessa fazenda.

O interlocutor narra que sua família se mudou de fazenda por diversas vezes. Só no município de Quirinópolis passaram por quatro fazendas diferentes e, por fim, se estabeleceram em uma, onde morou até conhecer sua esposa e se mudarem para as terras de um tio dela. No entanto, seus parentes venderam a terra e eles reiniciaram a migração, passando por várias fazendas nos municípios de Cachoeira Dourada, Quirinópolis, Jataí e Itumbiara (Goiás):

Aí eu vim para Quirinópolis de novo, toquei roça lá uns tempos, num deu certo, perdeu tudo, tinha muito sol. Aí eu vim embora para Jataí. Eu fiquei no Jataí muito tempo, mexendo com roça pra aqui pra li com uns fazendeiros. Trabalhei muito tempo, um punhado de anos vendendo pipoca, trabalhava na cidade e ficava na roça também. Vendi pipoca em Jataí muitos anos. Mas eu tocava roça, todo ano eu tocava minha roça.

A trajetória do Entrevistado 11 também é repleta de histórias dos lugares e fazendas pelas quais passou e relata: "de dez anos em diante eu já saí no mundo, sozinho". Nascido no Estado de São Paulo, no município de Fernandópolis, se mudou para Aparecida do Taboado, em seguida para Paranaíba, Cassilândia e Chapadão do Sul, no Mato Grosso do Sul e, finalmente, se estabeleceu em Jataí.

As trajetórias dos demais depoentes convergem, guardadas às devidas especificidades, com as aqui já relatadas no sentido do processo migratório, passando por várias regiões, estados e cidades, até chegarem e se fixar no município de Jataí. Marques (2000, p. 14) diz que este processo ocorre pelo fato de que

O campesinato brasileiro não é um enraizado, ele é um migrante e seu deslocamento tem sido determinado em grande parte pelo avanço da propriedade capitalista sobre a terra. Ao serem expulsos ou perderem sua propriedade, eles geralmente retornam a terra, mesmo que em outro lugar.

Vale considerar que os camponeses pesquisados ao chegarem no município de Jataí, onde residem atualmente, não tiveram suas migrações cessadas, tendo vivido em diversas fazendas, oscilando entre a cidade e o campo, como conta o Entrevistado 7: "eu cheguei aqui [em Jataí] dia 17 de fevereiro de 1971. Eu vim para Jataí, fui para rio verdinho".

Este sujeito diz que ficou quase um ano morando em uma fazenda, na região do rio verdinho, trabalhando e pegando empreitadas em fazendas vizinhas. Em seguida se mudou para cidade, pas- 
sando a morar numa residência alugada, de cômodo único, trabalhando como assalariado em uma cerealista, ao mesmo tempo em que "mexendo com a horta, na beira da cidade, à meia, com os hortaliceiros". Tal qual este sujeito, mais quatro originários do Estado da Bahia chegaram a Jataí e foram trabalhar em fazendas, depois se mudaram para cidade, estiveram assalariados e começaram a lidar com horta na periferia urbana e, por vezes, o faziam em conjunto, como relata o Entrevistado 8:

Eu saí da firma e eu de cada coisa faço um pouquinho. Aí o patrão, o filho do velho lá [dono da cerealista], me levou numa chacarazinha dele para poder fazer um banheiro. Chegando lá achei uma área de terra muito boa, com aguada, eu era invocado a mexer com horta e tinha um colega meu aqui [Entrevistado 2, também da Bahia], ele pegou e falou, 'vê se você consegue a terra lá, se você conseguir, nós trabalhamos juntos'. Aí eu fui.

Os depoimentos evidenciam que todas as migrações e mudanças são em busca de sobrevivência, tendo saído à procura da terra de trabalho e de vida. Conforme Carvalho (1999, p. 9), poderia se afirmar " [...] que o trabalhador rural sem terra é nômade geográfico e social. E este nomadismo social não está relacionado, necessariamente, à mobilidade social vertical, mas às suas estratégias de sobrevivência".

Cabe destaque o fato de, dentre os dezenove camponeses pesquisados, quatorze não serem procedentes do município de Jataí e, destes, onze terem ali chegado entre o final da década 1960 e início de 1980. Salienta-se que este período foi intenso no que tange às mudanças na agricultura brasileira, que já vinha se reestruturando desde a década de 1950, atingindo significativamente a região estudada a partir da década de 1970 .

\section{A LUTA PELA TERRA NO SUDOESTE DE GOIÁS}

O período no qual os camponeses pesquisados chegaram ao município de Jataí coincide com a conjuntura nacional de aprovação do Estatuto dos Trabalhadores Rurais e Estatuto da Terra e com a ascensão da modernização agrícola que era estendida ao Centro-oeste, no intuito de racionalizar, do ponto de vista capitalista, a ocupação do Cerrado. Estas transformações trouxeram consigo vários reflexos socioeconômicos, sendo a expropriação, seguida pelo êxodo rural, um dos maiores resultados do seu caráter excludente e segregador.

Ribeiro (2005) aponta que no ano de 1970 o Estado de Goiás apresentava uma população de 2.997.570 habitantes, sendo que desta $42,34 \%$ residia na cidade e 57,66\% no campo; já no ano de 2000 a população era de 4.994 .897 habitantes, sendo que $87,88 \%$ residia em áreas urbanas e apenas $12,12 \%$ no campo.

A mesma autora afirma que para o município de Jataí esta inversão se deu de forma ainda mais acentuada. Neste município, no ano de 1970 a população era de 41.374 pessoas, sendo que $65 \%$ residia na cidade e $35 \%$ no campo; no ano de 2000 a população era de 75.451 pessoas, com $92 \%$ residindo na cidade e $8 \%$ na zona rural (RIBEIRO, 2005).

Porém, vale considerar que o êxodo rural não é o limite deste processo. Outros reflexos socioeconômicos e ambientais gerados pela expansão das relações de produção capitalistas ao campo têm sido objeto de análise por parte de diversos estudiosos, a exemplo de problemas urbanos tratado por Ribeiro (2005), da precarização e das mudanças nas relações de trabalho, tratado por Mendonça (2004), dos problemas socioambientais demonstrados por Mendonça (2004) e Mazzeto-Silva (2009), como o desmatamento das áreas de Cerrado, a ameaça à função hidrológica das chapadas, à desvalorização de saberes tradicionais e à biodiversidade, também tratada, numa escala mais ampla, por Shiva (2003).

Articulada ao êxodo, a acentuação da concentração de terras foi um dos principais resultados da modernização agrícola, assentada em um modelo que dificulta o acesso e a permanência camponesa na terra. 
Dialeticamente, isso gera novas demandas, reconfigurando as lutas, onde camponeses que se vêem sem-terra, tendo suas possibilidades de reprodução ameaçadas, buscam mecanismos de retorno a terra. Foi neste contexto que se teve o envolvimento dos depoentes no processo de luta pela terra no município de Jataí.

Despertados pela constituição do Assentamento Íris Rezende Machado (Rio Paraíso), houve uma movimentação por parte do Sindicato dos trabalhadores Rurais de Jataí para agregar os trabalhadores sem terra a fim de promoverem as primeiras ocupações. Essa movimentação acompanhava o que vinha se dando em nível macro, em termos de ocupações de terra em todo o Centro-oeste e no Brasil.

Dados obtidos por meio do Banco de Dados de Luta Pela Terra (DATALUTA, 2008), demonstram que na região Centro-Oeste foram registradas 1.103 ocupações de terra no período de 1988 a 2007. Nesta região, o Estado que possui maior número de ocorrências é Mato Grosso do Sul, somando 551 ocupações, que tiveram seu ápice entre os anos de 1997 e 2001, sendo 38 em 1997; 85 em 1998; 116 em 1999; e 39 em 2001.

O Estado de Mato Grosso somou 138 ocupações, sendo que a maior quantidade destas ocorreu nos anos de 1996 (18 ocupações) e 1999 (16 ocupações), tendo seu ápice no ano de 2003 com 26 ocupações.

O Distrito Federal possui números menos expressivos, apresentando somente 39 ocupações, não tendo no banco de dados DATALUTA (2008) nenhum registro antes do ano de 1994. De todos os anos, o de 2005 foi o que mostrou índices mais elevados, somando 11 ocupações.

O Estado de Goiás ocupa o segundo lugar no ranking das ocupações no Centro-oeste no período recortado, contando 375 ocupações assim distribuídas anualmente:

Quadro 1 - Ocupações de terra no estado de Goiás

\begin{tabular}{|c|c|c|c|}
\hline ANO & QUANTIDADE & ANO & QUANTIDADE \\
\hline 1988 & 04 & 1998 & 19 \\
\hline 1989 & 02 & 1999 & 32 \\
\hline 1990 & - & 2000 & 16 \\
\hline 1991 & 01 & 2001 & 13 \\
\hline 1992 & 09 & 2002 & 09 \\
\hline 1993 & 07 & 2003 & 33 \\
\hline 1994 & 04 & 2004 & 48 \\
\hline 1995 & 10 & 2005 & 29 \\
\hline 1996 & 25 & 2006 & 25 \\
\hline 1997 & 64 & 2007 & 25 \\
\hline
\end{tabular}

Fonte: dados organizados pelas autoras com base no banco de dados DATALUTA (2008).

As ocupações de terra realizadas no Estado de Goiás foram promovidas por diferentes entidades e movimentos sociais, sendo a Comissão Pastoral da Terra (CPT) e o Movimento dos Trabalhadores Sem Terra (MST) os mais atuantes. Porém, isso não se reflete no Sudoeste de Goiás, conforme será tratado adiante.

Das 375 ocupações mostradas no Quadro 1, 68 foram registradas na microrregião Sudoeste de Goiás, que abrange 18 municípios situados na mesorregião Sul Goiano. No entanto, destes 18 municípios, o banco de dados DATALUTA só possui registros de 09 deles, a saber: Caiapônia, Chapadão do Céu, Doverlândia, Jataí, Montividiu, Perolândia, Rio Verde, Santa Helena de Goiás e Serranópolis.

Os outros 09 municípios dos quais não há informações no banco de dados utilizado como referência para a pesquisa são: Aparecida do Rio Doce, Aporé, Castelândia, Maurilândia, Mineiros, Palestina de Goiás, Portelândia, Santa Rita do Araguaia e Santo Antônio da Barra. Estes não estão contemplados neste trabalho. 
Quadro 2 - Ocupações de terra na microrregião sudoeste de Goiás

\begin{tabular}{|c|c|c|c|c|c|c|c|c|c|c|}
\hline $\begin{array}{l}\text { MUN. } \\
\text { ANO }\end{array}$ & Caiapônia & $\begin{array}{l}\text { Chapadão } \\
\text { do Céu }\end{array}$ & Doverlândia & Jataí & Montividiu & Perolândia & $\begin{array}{c}\text { Rio } \\
\text { Verde }\end{array}$ & Serranópolis & $\begin{array}{c}\text { Sta. } \\
\text { Helena }\end{array}$ & Total \\
\hline 1993 & & & & 02 & & & & & & 02 \\
\hline 1994 & & & 01 & & & & & & & 01 \\
\hline 1995 & & & 02 & & & & & & & 02 \\
\hline 1996 & & & 02 & 01 & 03 & & & & & 06 \\
\hline 1997 & & & 05 & 06 & & & 04 & & 01 & 16 \\
\hline 1998 & & & & 02 & & 01 & & & & 03 \\
\hline 1999 & 03 & 02 & 01 & 01 & & & & & & 07 \\
\hline 2000 & & & 02 & & & 01 & & & & 03 \\
\hline 2001 & & 01 & & & & & & 01 & & 02 \\
\hline 2002 & 02 & & & & 01 & & & & & 03 \\
\hline 2003 & & & & 01 & & 01 & & & 03 & 05 \\
\hline 2004 & 01 & 02 & & 03 & & & & & & 06 \\
\hline 2005 & & 02 & & 01 & & & & & & 03 \\
\hline 2006 & & & & 03 & & & 01 & & & 04 \\
\hline 2007 & & & & 04 & & & 01 & & & 05 \\
\hline Total & 06 & 07 & 13 & 24 & 04 & 03 & 06 & 01 & 04 & 68 \\
\hline
\end{tabular}

Fonte: dados organizados pelas autoras com base no banco de dados DATALUTA (2008).

Vale ressaltar que os números do quadro acima não contêm informações do Instituto Nacional de Colonização e Reforma Agrária (INCRA), pois seus dados não nos foram disponibilizados. Isso, somado ao fato de o Banco de Dados DATALUTA não contemplar nove municípios no período recortado, tampouco dados da região anterior a 1993, sugere que o número de ocupações seja maior do que o que se tem registrado e catalogado. Porém, os objetivos e os prazos estabelecidos para a realização da pesquisa não permitiram desenvolver uma metodologia para a coleta destes dados.

Os dados do quadro 2 demonstram que, entre os municípios goianos analisados, Jataí aparece em primeiro lugar no ranking de ocupações de terras, totalizando 24 , o que representa $35 \%$ do total. Em segundo está o município de Doverlândia com 13 ocupações, representando 19\%. Juntos, estes dois municípios representam 54\% das ocupações de terras no Sudoeste de Goiás no período demonstrado.

As ocupações de terra em Jataí possuem algumas especificidades, pois, diferente de outros municípios do Estado Goiás, como a Cidade de Goiás, Itapuranga e Itaberaí, estas não foram organizadas com apoio da CPT e do MST.

A não atuação da CPT foi alvo da investigação de Leal (2006) que afirma que isso se dá em função de uma estreita ligação da Igreja católica e de seus membros com os grandes proprietários da região. A autora destaca que a Diocese de Jataí é detentora de grande patrimônio imobiliário, alvo, em diversos momentos, de ocupações e litígios. Por isso a Diocesse sempre se posicionou firme e abertamente contra os conflitos por terra na região.

Um exemplo das ocupações envolvendo terra da Igreja foi a realizada em 20 de agosto de 2006 (DATALUTA, 2008), da Fazenda Seminário Nossa Senhora de Guadalupe, pertencente àquela Diocese. A fazenda possuía cerca de 1.300 hectares e, na ocasião, estava arrendada para o cultivo de soja. A ocupação se deu por parte de 50 famílias de trabalhadores rurais sem terra e, após anos de litígio, atualmente compõe o Projeto de Assentamento Guadalupe. 
Quanto à atuação do MST na Microrregião Sudoeste de Goiás, os dados do DATALUTA (2008) demonstram que a primeira ocupação realizada pelo Movimento nos nove municípios, dos quais se têm informações, foi no ano de 2001 em Serranópolis. Das 68 ocupações registradas (ver quadro 2) na Microrregião Sudoeste de Goiás, apenas 10 foram realizadas pelo MST.

No Estado de Goiás, a ação do MST, até o momento, esteve mais centrada nas cidades próximas à capital e ao Sul do Estado, principalmente naquelas cortadas pela estrada de ferro (KATZER, 2005), sendo que na microrregião estudada, no período em que houve maior número de ocupações de terras, este movimento esteve pouco atuante. Isso pode ser considerado como resultado de uma blindagem da região por parte do agronegócio, de forma a dificultar a ação dos movimentos sociais, a evitar a visibilidade da questão agrária e a fazer crer que não há manifestação contrária ao agronegócio na região.

No entanto, o MST tem firmado, nos últimos anos, uma presença mais atuante na região, com destaque para o Acampamento Padre Josimo que tem agregado centenas de famílias e orientado diversas ações no município de Jataí e na microrregião Sudoeste de Goiás.

No município de Jataí, conforme demonstrado no Quadro 2, foram realizadas vinte e quatro ocupações de terra entre 1993 e 2007. Destas, três foram organizadas pelo MST, nove pelo Movimento Terra, Trabalho e Liberdade (MTL) e nove pelo STR - Jataí, sendo que as outras três não possuem registros de quais movimentos as realizaram .

\section{ELOS ENTRE AS TRAJETÓRIAS DOS DEPOENTES E INSERÇÃO DOS MESMOS NO PROCESSO DE LUTA PELA TERRA}

As ocupações realizadas com apoio do Sindicato dos Trabalhadores Rurais -Jataí deram origem ao Projeto de Assentamento Rio Claro (dentre outors) e teve influência marcante nas trajetórias socioespaciais dos sujeitos pesquisados e no movimento de luta pela terra no município.

Katzer (2005) relata que o primeiro movimento de luta pela terra em Jataí se deu no ano de 1985, quando os camponeses filiados ao STR - J se mobilizaram e partiram para uma ocupação que deu origem ao primeiro assentamento do município, o Projeto de Assentamento Íris Rezende Machado, mais conhecido como Rio Paraíso .

O fato de ter "saído" esta terra (que constituiu o P.A. Íris Rezende Machado) incentivou os demais trabalhadores rurais sem terra da região, tanto os que trabalhavam no campo, quanto os que se encontravam nas cidades, levando-os a se filiarem no STR - J, na esperança de que novas terras "saíssem", como relatam os Entrevistados 5 e 6:

Sabia que ganhava terra. Já tinha saído aquela Rio Paraíso. Naquelas épocas uns parentes da N.[esposa] foram para lá, nesse Rio Paraíso. Aí eu filiei lá e fiquei desde 1982. Aí arrumaram essa área aqui perto para nós. O sindicato descobriu esta terra aqui e aí nós filiamos.

O Sindicato dos Trabalhadores Rurais de Jataí foi o principal meio de ingresso dos depoentes na luta pela terra e o responsável pelos dois movimentos que ali emergiram, um que deu origem ao P.A. Rio Paraíso (Íris Rezende Machado) e outro que deu origem a vários assentamentos, neste e em outros municípios da microrregião, inclusive o assentamento pesquisado (Rio Claro).

A luta pela terra foi um marco nas trajetórias socioespaciais dos sujeitos pesquisados e significa o ponto de convergência entre todos, num período árduo de suas vidas. $\mathrm{O}$ entrevistado 7 narra fragmentos desta história:

Juntamos aquele grupo, aquela fazenda estava parada, a gente ia para lá. Aí foi chegando ao conhecimento do sindicato, pelo INCRA, que se houvesse a possibilidade de alguma fazenda estar à toa, podia dar uma observada nela e podia entrar. [...] Fui um dos primeiros. Ainda lembro quando nós, lá na beira do asfalto, na beira da ponte, começamos no dia 02 de agosto, entramos oito horas da manhã. Muita turma. Em 1996. Oito horas da manhã. Nós éramos muitos. 
Este depoimento traduz o significado da luta para os camponeses, que guardam em suas memórias o ano, o dia e a hora exata em que se deu a primeira ocupação de terra que originou o acampamento e, posteriormente, o assentamento em que vivem.

O movimento de luta pela terra do qual os depoentes participaram teve início a partir de uma ocupação realizada na Fazenda Cambauvinha, no dia 02 de agosto de 1996. Desta ocupação foi criado o MTRST - Movimento dos Trabalhadores Rurais Sem Terra do Município de Jataí - GO e o acampamento Cambauvinha.

Os relatos apontam que após realizarem a ocupação tiveram que sair das terras, pois o fazendeiro conseguiu expulsá-los com uma liminar judicial.

Ao serem despejados montaram novo acampamento, às margens da BR 158, no sentido Jataí - Caiapônia, no entroncamento que dá acesso ao município de Perolândia. Ali estiveram reunidas mais de 500 famílias. Identifica-se, por meio dos depoimentos, que o acampamento abarcou cerca de seis quilômetros, ao longo dos dois lados da rodovia.

Por ser o acampamento muito extenso, as famílias foram divididas em "turmas" e passaram a ocupar outros locais, pois houve o entendimento de que a área pleiteada, quando ocorresse a desapropriação, não contemplaria todas as famílias, conforme trata o relato:

Ia dividindo pra ir pra outras áreas. Aí arrumava uma turma e ia. Aqui não cabia todo mundo. Tinha aqueles que iam lá ver, já controlava uma turma e levava pra lá, tantas pessoas. [...] Foi aí que o pessoal ia saindo. Uns foram para o [acampamento] Santa Rita, outros foram lá para aquele Chapadão [se refere à cidade de Chapadão do Céu], aquele assentamento Pratinha. Só na beira desse Rio Verde aí tem uns três assentamentos que saíram daqui. Estavam junto com nós. Lá pro [município de] Montividiu, lá também foi gente daqui (ENTREVISTADO 5).

Percebe-se que a partir dessa dinâmica vários acampamentos foram criados em lugares diferentes, dando origem a vários assentamentos, como o P.A Santa Rita em Jataí, P.A Rio Verdinho em Rio Verde, P. A. Pratinha em Chapadão do Céu, dentre outros na microrregião Sudoeste de Goiás.

O Entrevistado 4 relata que, após a divisão das "turmas", a que formou o P. A. Rio Claro ocupou uma área na Fazenda Campos Elísios, próximo à BR 158. Os interlocutores afirmam que eram constantes as ocupações: "olha, da beira do [córrego] São Pedro, até ali, nós pegamos treze liminares, treze ocupações e treze saídas também (ENTREVISTADO 7)".

Os depoimentos apontam o período em que estiveram acampados no corredor da BR-158 como o mais difícil de ser transposto no decorrer de suas trajetórias sociespaciais, passando por dificuldades diversas, como intempéries da natureza, falta de água, condições precárias de moradia, de saúde, de escolas e de trabalho e que todas as dificuldades eram enfrentadas movidas pelo vislumbre de ter a terra, a autonomia e a liberdade, comprometidas a muito tempo; pela possibilidade de continuarem a existir na terra, enquanto camponeses.

No ano de 1999 as famílias, que hoje compõem o assentamento Rio Claro, ocuparam definitivamente a Fazenda Campos Elísios montando o acampamento no local que pleiteavam para a desapropriação. A saída do acampamento às margens da rodovia amenizou algumas dificuldades e lhes deu força e motivação para prosseguirem na luta, mas ainda enfrentariam vários percalços no período de espera até a desapropriação da área.

No ano de 2001 a imissão de posse foi expedida pelo INCRA. No entanto, o proprietário recorreu à justiça e conseguiu a reintegração de posse da fazenda. As famílias continuaram na luta pela desapropriação e em 2006 foram assentadas de forma definitiva, dez anos depois de terem iniciado suas trajetórias na luta pela terra.

A luta foi o modo encontrado pelos camponeses para findar suas trajetórias incertas, fixando-se na terra e procurando meios de reestabelecer seus modos de vida. Por meio da terra conquistada, foram aos poucos constituindo suas territorialidades. 
Nesse sentido, concordamos com Oliveira (2007, p. 11) quando menciona que

O campesinato deve, pois, ser entendido como classe social que ele é. Deve ser estudado como um trabalhador criado pela expansão capitalista, um trabalhador que quer entrar na terra. $\mathrm{O}$ camponês deve ser visto como um trabalhador que, mesmo expulso da terra, com freqüência a ela retorna, ainda que para isto tenha que (e)migrar. Dessa forma, ele retorna à terra mesmo que distante de sua região de origem. É por isso que boa parte da história do campesinato sob o capitalismo é uma história de (e) migrações.

As famílias envolvidas nas ocupações que originaram o P. A. Rio Claro vinham de um longo processo de migração pelo território brasileiro, empurradas pela modernização da agricultura e impulsionadas pelo anseio de se fixar numa terra onde pudessem viver e trabalhar.

A convergência destas famílias para o Sudoeste de Goiás se deu em função da propaganda desta região como o lugar de progresso em função das atividades agrícolas. No entanto, uma vez instalados na região, os camponeses tomaram consciência de que a agricultura propagandeada se dava em moldes organizacionais, econômicos e técnicos que não comportavam o modo de vida camponês.

O P.A. Rio Claro, assim como tantos outros assentamentos no Brasil, é fruto deste contexto de demandas de trabalhadores sem terra, que, após longos períodos de migrações, se fixaram numa região altamente impactada pelas políticas de modernização agrícola, cujos reflexos se deram na redução dos empregos rurais e na concentração fundiária, motivando-os a entrar na luta pela terra.

De acordo com dados do DATALUTA (2008), desde 1984 foram criados no país 8.366 assentamentos, como fruto da pressão das lutas contra a desigual distribuição de terras no Brasil, que expressa a luta de classes no interior do sistema capitalista, já que a luta dos trabalhadores sem-terra é um enfrentamento contra o próprio capital.

Tais dados demonstram que destes 8.366 assentamentos criados no Brasil, 1.863 estão situados na Região Norte; 3.848 na Região Nordeste; 1.134 na Região Centro-Oeste; 788 na Região Sul; e 733 na Região Sudeste. Sendo que na região Centro-oeste, 370 foram criados no Estado de Goiás.

Dos 370 projetos de assentamento do Estado de Goiás, 58 foram criados na Microrregião Sudoeste, conforme pode ser visualizado no quadro 3.

No município de Jataí foram constituídos 6 projetos de assentamentos: o P.A. Íris Rezende Machado (Rio Paraíso) no ano de 1989, com 176 famílias, numa área de $5.562 \mathrm{~m}^{2}$; o P.A. Santa Rita em 1998, com 23 famílias e área de $961 \mathrm{~m}^{2}$, o P.A. Rio Claro no ano de 2001, com 17 famílias e $639 \mathrm{~m}^{2}$. Já os demais foram constituídos no ano de 2007: o P.A. Nossa Senhora de Guadalupe, com $1.367 \mathrm{~m}^{2}$ e 85 famílias; o P.A. Rômulo Souza Pereira, com 90 famílias numa área de 2.041 $\mathrm{m}^{2}$; e o P.A. Terra e Liberdade, com o total de 162 famílias e área de $2.927 \mathrm{~m}^{2}$. Ao todo, entre 1989 e 2007 foram assentadas neste município 553 famílias numa área de $13.500 \mathrm{~m}^{2}$.

Ao fazer o resgate das trajetórias socioespaciais dos depoentes buscou-se elementos para apontar que a posterior inserção na luta pela terra é resultante da expropriação sofrida pelos mesmos, que, após décadas buscando terra para trabalhar e viver, compreenderam que não haveria outro meio de acessá-la que não por meio da reforma agrária e esta, por sua vez, só se daria por meio da luta.

As trajetórias, acompanhadas de constantes migrações, privações e desgostos, serviram como impulso à inserção na luta pela terra, já que o longo tempo de constantes mudanças entre fazendas, municípios, estados e regiões, chegando a três décadas no caso de alguns depoentes, esclareceu que havia uma realidade no campo brasileiro, independente de região, tendendo a deixar o acesso a terra cada mais remoto.

Ainda, o retorno às trajetórias serve para investigar o significado da modernização agrícola para os processos migratórios, o êxodo rural e a constituição dos movimentos de luta pela terra. A pesquisa aponta que, do universo pesquisado, $74 \%$ dos depoentes são originários de outros municípios, estados e regiões, tendo se inserido na luta pela terra e estando atualmente assentados após longos períodos de migrações decorrentes, sobretudo, dos processos e relações em curso após a modernização agrícola. 
Quadro 3 - Número de projetos de assentamentos criados na microrregião sudoeste de Goiás entre 1989 e 2007

\begin{tabular}{|c|c|c|c|c|c|c|c|c|c|c|}
\hline MUN. & Caiapônia & $\begin{array}{c}\text { Chapadão do } \\
\text { Céu }\end{array}$ & Doverlândia & Jataí & Mineiros & Perolândia & $\begin{array}{c}\text { Rio } \\
\text { Verde }\end{array}$ & $\begin{array}{l}\text { Sta. } \\
\text { Helena }\end{array}$ & $\begin{array}{l}\text { Sta. Rita } \\
\text { do } \\
\text { Araguaia }\end{array}$ & TOTAL \\
\hline 1989 & & & & 01 & & & & & & 01 \\
\hline 1991 & & & 01 & & & & & & & 01 \\
\hline 1995 & & & 01 & & & & & & & 01 \\
\hline 1996 & & & 02 & & & & & & & 02 \\
\hline 1997 & & & 03 & & & & 01 & & & 04 \\
\hline 1998 & & 02 & 04 & 01 & 01 & 01 & 03 & 02 & & 14 \\
\hline 1999 & 02 & & 01 & & & & 02 & 01 & & 06 \\
\hline 2000 & & 01 & & & & 01 & 01 & & & 03 \\
\hline 2001 & & & 01 & 01 & & & & & & 02 \\
\hline 2002 & 03 & & & & & & 02 & & & 05 \\
\hline 2004 & & & 01 & & & & & & & 01 \\
\hline 2005 & 01 & & & & 02 & & & & & 03 \\
\hline 2006 & 06 & & & & 01 & & & & 02 & 09 \\
\hline 2007 & 01 & & 01 & 03 & & & & & 01 & 06 \\
\hline TOTAL & 13 & 03 & 15 & 06 & 04 & 02 & 09 & 03 & 03 & 58 \\
\hline
\end{tabular}

Fonte: dados organizados pelas autoras com base no banco de dados DATALUTA (2008).

Os números de ocupações e assentamentos na região em estudo, em Goiás e no Centro-oeste, foram apresentados ao longo do texto no intuito de esclarecer que na medida em que aumenta a inserção de uma dada região no processo de modernização agrícola, aumenta, também, a pressão dos movimentos de luta pela terra. Já que se têm reduzidos os empregos no campo e as áreas destinadas à agricultura camponesa, ao mesmo tempo em que aumenta a atração de novos trabalhadores imigrantes.

\section{CONSIDERAÇÕES FINAIS}

Os problemas oriundos da questão agrária no Brasil são de fundo político, inerentes à sua formação territorial e se agravou com a modernização agrícola, com destaque para a redução das áreas destinadas à agricultura camponesa, diminuição dos empregos no campo e aumento da concentração de terras.

Reflexos desta conjuntura foram verificados nas trajetórias socioespaciais dos depoentes, sobretudo no que diz respeito à acessibilidade a terra: esta se tornou mais remota para os camponeses sem-terra e/ou com pouca terra, que necessitariam ampliá-la para oportunizar a família condições de trabalho e de vida, provocando desequilíbrio na relação trabalho-consumo do núcleo familiar e impulsionando as migrações.

A região em estudo atraiu (e continua atraindo) muitos trabalhadores, em função da visibilidade dada pelo agronegócio. Assim, ocorreu a convergência de camponeses de diversas regiões do Brasil que, após longos períodos de migrações e ao compreenderem que o modelo agrícola regional não os priorizariam no seu processo constitutivo, se uniram no movimento de luta pela terra. Aí há o encontro entre centenas de camponeses até então desconhecidos entre si, mas com suas histórias e trajetórias repletas de convergências.

No caso estudado, o Sindicato dos Trabalhadores Rurais de Jataí foi o condutor das primeiras ocupações regionais, agregando os camponeses pesquisados e outros, na sua maioria de diferentes 
municípios e regiões que para ali tinham se dirigido, dando origem a grande parte dos assentamentos dos municípios de Jataí, Rio Verde, Montividiu, Chapadão do Céu, dentre outros.

Daí decorreu o embrião da luta pela terra na Microrregião Sudoeste de Goiás e no município de Jataí com algumas especificidades, como o não envolvimento, até hoje, da CPT e a pouca atuação, naquele momento, do MST, bem como com o desdobramento de dezenas de assentamentos na região oriundos de um único acampamento.

A pesquisa buscou dar visibilidade à luta pela terra na região estudada pelo fato de que este tema tem sido ali abafado por setores ligados ao agronegócio, principalmente nas esferas política e econômica, com reflexos na esfera acadêmica.

Os dados e as reflexões aqui apresentadas buscaram contemplar, por um lado, as trajetórias socioespaciais de camponeses que trazem nas suas histórias de vidas a experiência das migrações e, por outro, as ocupações de terra e a constituição dos assentamentos na microrregião Sudoeste de Goiás e no município de Jataí, considerando que os dados da pesquisa de campo apontam que, dentre o universo pesquisado, $74 \%$ dos camponeses atualmente assentados no P. A. Rio Claro constitui-se de sujeitos oriundos de outros municípios e/ou regiões.

\section{AGRADECIMENTOS}

Convém destacar, no delineamento do presente paper, importância de financiamento concedido pela CAPES.

\section{REFERÊNCIAS BIBLIOGRÁFICAS}

ALY JUNIOR, Osvaldo. Políticas públicas e sustentabilidade no desenvolvimento dos assentamentos do estado de São Paulo: um balanço dos anos 2003-2005. In: FERRANTE, Vera Lúcia Silveira Botta; ALY JUNIOR, Osvaldo (Orgs). Assentamentos Rurais: impasses e dilemas (uma trajetória de 20 anos). São Paulo, INCRA, Superintendência Regional de São Paulo: Copyright, 2005. p. 175-198.

ALMEIDA, Rosemeire Aparecida de. (Re)criação do campesinato, identidade e distinção: a luta pela terra e o habitus de classe. São Paulo: Editora UNESP, 2006.

BOMBARDI, Larissa Mies. O bairro reforma agrária e o processo de territorialização camponesa. São Paulo: Annablume, 2004.

CARVALHO, Horácio Martins de. A interação social e as possibilidades de coesão e de identidade sociais no cotidiano da vida social dos trabalhadores rurais nas áreas oficiais de reforma agrária no Brasil. Curitiba, 1999. Disponível em: http://www.nead.gov.br/portal/nead/arquivos/view/textos-digitais/Artigo/ arquivo_15.pdf. Acesso em out. 2010.

CHAYANOV, Alexander Vasilievich. La organización de la unidad campesina. Buenos Aires: Ediciones Nueva Visón, 1974. Traduzido por Rosa María Rússovich.

CIRQUEIRA, Diogo Marçal. Entre o corpo e a teoria: a questão étnico-racial na obra e trajetória socioespacial de Milton Santos. Goiânia: s.n., 2010. Dissertação (Mestrado em Geografia) - Instituto de Estudos Sócio-Ambientais (IESA), Universidade Federal de Goiás, Goiânia (GO), 2010.

COCA, Estevan Leopoldo de Freitas; FERNANDES, Bernardo Mançano. A atualidade da questão agrária brasileira: uma discussão sobre os conceitos de reforma agrária e sobre a tipologia de assentamentos rurais. Revista ABRA, Vol. 35, jan./dez. 2008, p. 21-40.

DATALUTA, Banco de Dados da Luta pela Terra. Relatório 2008. Presidente Prudente: FCT/ UNESP, São Paulo, 2008.

DIAS, Mariza Souza. Pequenos produtores rurais de Jataí: caracterização e relevância. Jataí: s.n., 2008. Monografia (Bacharelado em Geografia) - Departamento de Geografia, Universidade Federal de Goiás Campus Jataí, Jataí (GO), 2008.

FERREIRA, Débora Ferguson. Análise das transformações recentes na atividade agrícola da região sudoeste de Goiás. 1970/1995-6. 2001. 145 f. Dissertação (Mestrado em Desenvolvimento Econômico) Instituto de Economia, Universidade Federal de Uberlândia, Uberlândia, 2001. 
GOHN, Maria da Glória. Teoria dos movimentos sociais: paradigmas clássicos e contemporâneos. São Paulo: Edições Loyola, 2007.

GUIMARÃES, Juliana Carneiro. As trajetórias socioespaciais dos camponeses do Assentamento Rio Claro em Jataí-GO. 2011. 130 f. Dissertação (Mestrado em Geografia) - Departamento de Geografia da Universidade Federal de Goiás, Campus Jataí. Jataí (GO), 2011

KATZER, Rosália Teresinha. Da labuta para a conquista da terra aos labirintos da sojicultura: um olhar sobre o Assentamento Rio Paraíso, em Jataí (GO). Dissertação (Mestrado em Geografia) - Instituto de Estudos Sócio-Ambientais (IESA), Universidade Federal de Goiás, Goiânia (GO), 2005.

KAUTSKY, Karl. A questão Agrária. PORTO: Portucalense Editora, 1972. Tradução de João Antunes.

LEAL, Cátia Regina Assis Almeida. Arapuca armada: ação coletiva e práticas educativas na modernização agrícola do sudoeste goiano. 2006. 259 f. Tese (Doutorado em Educação) - Faculdade de Educação, Universidade Federal de Goiás, Goiânia, 2006.

MARQUES, Marta Inês Medeiros. De sem-terra a "posseiro", a luta pela terra e a construção do território camponês no espaço da reforma agrária: o caso dos assentados nas fazendas Retiro e Velha - GO. 2000. 240 f. Tese (Doutorado em Geografia Humana) - Universidade de São Paulo, São Paulo, 2000.

MAZZETTO-SILVA, Carlos Eduardo. O cerrado em disputa: apropriação global e resistências locais. Brasília: Confea, 2009.

MENDONÇA, Marcelo Rodrigues. A urdidura espacial do capital e do trabalho no Cerrado do Sudeste Goiano. São Paulo: s.n., 2004. Tese (Doutorado em Geografia) - Faculdade de Ciências e Tecnologia, Universidade Estadual Paulista, Presidente Prudente (SP), 2004.

MOURA, Margarida Maria. Camponeses. São Paulo: Editora Ática, 1988.

OLIVEIRA, Ariovaldo Umbelino de. Modo capitalista de produção, agricultura e reforma agrária. São Paulo: Labur Edições, 2007.

PAULINO, Eliane Tomiasi; ALMEIDA, Rosemeire Aparecida de. Terra e Território: a questão camponesa no capitalismo. São Paulo: Expressão Popular, 2010.

RIBEIRO, Dinalva. Donizete. Agricultura “caificada" no Sudoeste de Goiás: do bônus econômico ao ônus sócio-ambiental. 2005. 265 f. Tese (Doutorado em Geografia) - Universidade Federal Fluminense, Niterói, 2005.

SHANIN, Teodor. A definição de camponês: conceituações e desconceituações - o velho e o novo em uma discussão marxista. Revista NERA, Presidente Prudente, ano 8, n. 5, p. 1-21, jul/dez 2005.

SHIVA, Vandana. Monoculturas da mente: perspectivas da biodiversidade e da biotecnologia. São Paulo: Editora Gaia, 2003.

WOORTMANN, Ellen F. O saber tradicional camponês e inovações. In: OLIVEIRA, Ariovaldo Umbelino de; MARQUES, Marta Inês Medeiros (Orgs.). O campo no século XXI: território de vida, de luta e de construção da justiça social. São Paulo: Editora Paz e Terra, 2004.

Trabalho enviado em fevereiro de 2011 Trabalho aceito em maio de 2011 